\title{
Alterations of neocortical pyramidal neurons: turning points in the genesis of mental retardation
}

\section{Alberto Granato* and Andrea De Giorgio}

Department of Psychology, Catholic University, Milan, Italy

Edited by:

John Vijay Sagar Kommu, National

Institute of Mental Health and

Neurosciences, India

Reviewed by:

Rajshekhar Bipeta, Gandhi Medical

College and Hospital, India

T. S. Sowmya Bhaskaran, National

Institute of Mental Health and

Neurosciences, India

*Correspondence:

Alberto Granato, Department of

Psychology, Catholic University, Largo

A. Gemelli 1, Milan 20123, Italy

e-mail: alberto.granato@unicatt.it
Pyramidal neurons (PNs) represent the majority of neocortical cells and their involvement in cognitive functions is decisive. Therefore, they are the most obvious target of developmental disorders characterized by mental retardation. Genetic and non-genetic forms of intellectual disability share a few basic pathogenetic signatures that result in the anomalous function of PNs. Here, we review the key mechanisms impairing these neurons and their participation in the cortical network, with special focus on experimental models of fetal exposure to alcohol. Due to the heterogeneity of PNs, some alterations affect selectively a given cell population, which may also differ depending on the considered pathology. These specific features open new possibilities for the interpretation of cognitive defects observed in mental retardation syndromes, as well as for novel therapeutic interventions.

Keywords: apoptosis, dendrites, calcium spikes, fetal alcohol spectrum disorders, dendritic spines
Santiago Ramón y Cajal referred to the neocortical pyramidal neuron (PN) as "La noble y enigmática célula del pensamiento" (the noble and enigmatic cell of thought) (1). These glutamatergic, excitatory neurons represent the vast majority of neocortical cells (about $80-90 \%$ ), the remaining being constituted by GABAergic, inhibitory interneurons. Surprisingly and contrary to what one may expect, cortical interneurons, though minor in number, are characterized by a great variety of anatomical features, electrophysiological properties, and synaptic attributes [see Ref. (2) for review]. Conversely, PNs are often conceived as a rather homogeneous population. However, the principal neurons of the cerebral cortex are far from being identical to each other, since they show both evident and more subtle differences (Figure 1). In the present mini-review, we will first provide some examples of how PNs represent a heterogeneous population. Then, while it is quite obvious that developmental disorders associated with mental retardation (MR) target the main structure involved in cognitive functions (i.e., the cerebral cortex) and its majority neurons, we try to answer the question whether given subpopulations or functional features of PNs are preferentially affected. We focus mainly on the effects of fetal exposure to alcohol (see Figure 2), highlighting analogies and differences with other developmental disorders associated with MR.

\section{HETEROGENEITY OF PNs}

The difference among PNs is already apparent at a first glance of histological sections and is related to their radial position within the six-layered neocortical sheet. Besides the obvious morphological difference (short vs long apical dendrites), supragranular (layer 2/3; L2/3) and infragranular (layer 5; L5) PNs participate differently to the flow of information in the canonical microcircuit of the cortical column (8). Differences between supra- and infragranular layers can be observed also when looking at the more subtle, intrinsic electrophysiological properties. For instance, L2/3 neurons display less hyperpolarization-activated currents $\left(I_{h}\right)$, compared to L5 neurons (9).

The analysis of the fine columnar connections makes it possible to further distinguish subpopulations within L2/3 neurons. In the barrel cortex, for instance, lemniscal and paralemniscal afferents target PNs located at different depths in the supragranular layers (10). In the rodent visual cortex, L2/3 neurons are selectively interconnected to form fine-scale, distinct subnetworks (11).

Layer 5 PNs can be also further subdivided into subsets featuring discrete properties. Based on morphology, electrophysiology, and functional connectivity, L5 PNs are classified into intrinsically bursting and regular spiking. The former have the tendency of firing bursts of action potentials in response to steps of depolarizing current, usually display a prominent apical tuft in layer 1 (thicktufted), and project to subcortical targets. The latter fire trains of action potentials with constant interspike intervals, have a slender apical dendrite, and project mainly to other cortical areas (12-14). Within layer 5, PNs belonging to the sparse L5a and the densely populated L5b are also clearly distinguishable, according to differences concerning functional and connectional properties $(15,16)$. Even when L5 PNs project to the same subcortical target, they may be involved in different functional circuits, as it has been proposed for cortico-striatal neurons sustaining the direct and indirect pathways of the basal ganglia, respectively [(17); but see Ref. (18)]. The parcelation of PNs according to their radial distribution is further complicated by the heterogeneous population of layer 6 neurons (19). The apical dendrites of these cells are unusual, as they, unlike those of other PNs, do not reach superficial layers, although sharing many electrophysiological properties with other neocortical PNs (20).

If the uneven properties of $\mathrm{PNs}$ along the radial cortical dimension reflect the structure-function relationship within the column microcircuit, equally outstanding is the diversity along the tangential dimension. In this regard, the complexity of the dendritic tree 


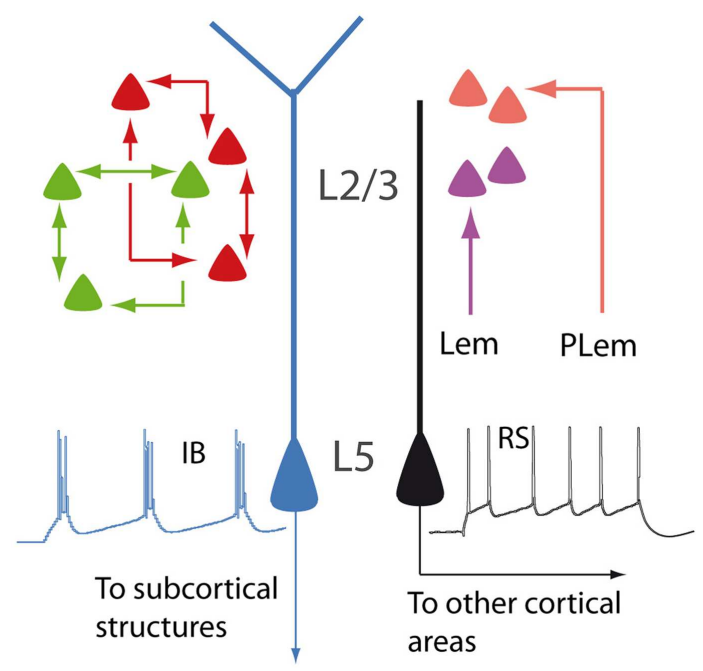

FIGURE 1 | Schematic illustration showing different types of PNs. In layer $2 / 3$, neurons are interconnected to form distinct subnetworks (green and red cells). In the barrel cortex, lemniscal (Lem) and paralemniscal (PLem) afferents target different subpopulations (purple and orange cells). In layer 5, regular spiking PNs (RS, black) and intrinsically bursting PNs (IB, blue) display different dendritic morphologies and different projections.

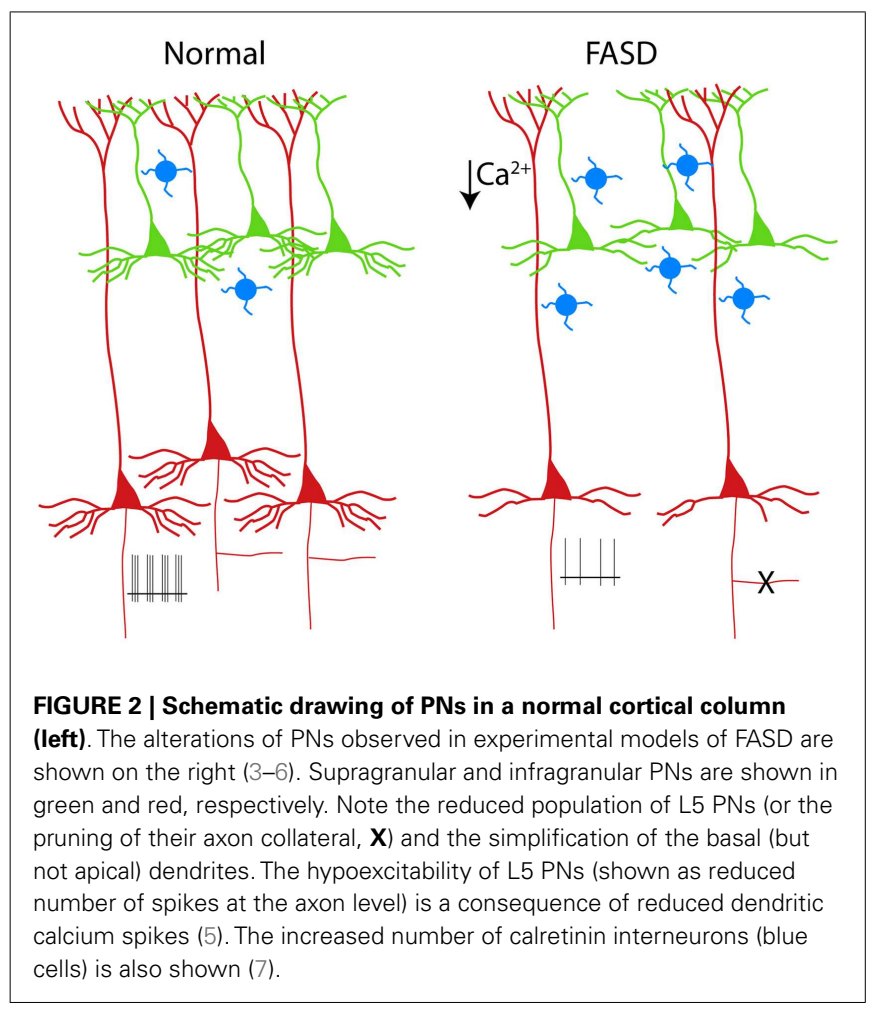

increases as one moves from primary sensory to higher order areas, reaching the most complex pattern in the prefrontal cortex (21). Further, the prefrontal cortex contains a large number of unusual PNs, which display an early bifurcation of the apical dendrite, whose total length is therefore susbstantially increased (22).
We have briefly outlined the laminar and regional heterogeneity of PNs. However, the reader should bear in mind that, even if neocortical PNs were homogeneous across cortical areas and layers, nonetheless each of them would represent the most complex neuron of the mammalian brain. Let us consider, for example, the L5 PN. Its apical dendrite extends through most of cortical thickness and is thus ideally suited for translaminar integration. In addition, the long, apparently homogeneous dendritic arbor of these neurons features specific functional properties: basal dendrites and the apical tufts are dominated by NMDA spikes, while $\mathrm{Ca}^{2+}$ spikes sustained by voltage-gated channels prevail in the distal apical trunk (23). Finally, dendritic, axon, and somatic domains of L5 PNs are targeted by different types of inhibitory interneurons (24). In summary, even the single PN is a complex world itself, able to integrate feedforward ascending input and feedback connections to generate the cognitive performance (25).

\section{APOPTOSIS}

Early exposure to alcohol, whose effects are globally referred to as fetal alcohol spectrum disorders (FASD), are well known causes of mental retardation. There are manifold factors involved in the neurodevelopmental toxicity of ethanol, which is critically dependent on the dose and time of exposure [see Ref. (26), for review]. Experimental models of FASD allow a tight control of alcohol exposure and help to dissect out the mechanisms operant at different developmental stages. When rodents are exposed during prenatal life, alcohol is more likely to interfer with the proliferation of neuron precursors and/or with the migration of cortical cells $(27,28)$. By contrast, when rodents are given alcohol during the first two postnatal weeks [corresponding to the third trimester of gestation in humans, see Ref. (29)], a massive apoptosis occurs in several brain structures, including the cerebral cortex (30). The third trimester equivalent is characterized by intense synaptogenesis and the alcohol-induced apoptosis is thought to be caused by the simultaneous blockade of NMDA receptors and activation of GABA receptors (31). The apoptosis observed in the neocortex after postnatal alcohol exposure in rodents seems to affect mainly infragranular PNs, as demonstrated by the selective presence of molecular markers of apoptotic susceptibility, such as caspase 3 and the low-affinity neurotrophin receptor (p75 NTR), in L5 cells $[(3,32)$; see Figure 2]. The prevailing involvement of infragranular PNs is also suggested by the increased ratio between supragranular and infragranular PNs sustaining the cortico-cortical associative projections (4). Notably, the vulnerability of these neurons to apoptosis outlasts the alcohol exposure, since an increased immunoreactivity for p75 NTR is observed several days after withdrawal (3). In a different experimental model of MR, reproducing the congenital hypothyroidism, the increased apoptosis is associated to upregulation of p75 NTR (33). In this case, however, the apoptotic cells are confined to supragranular instead of infragranular layers (33).

The unbalanced weights of supra- and infragranular layers, as observed in different types of MR, can yield important functional consequences. For instance, sensory and memory processing carried out by the same cortical area are mediated by opposite flows of interlaminar signals [supragranular $\rightarrow$ infragranular and infragranular $\rightarrow$ supragranular, respectively; see Ref. (34)]. 
It is worth noting here that experimental models mimicking other types of MR are characterized by a reduced rate of naturally occurring cell death, rather than by increased apoptosis. This is the case for FMR1 mutants (reproducing the fragile X syndrome) and for the Rett syndrome as well $(35,36)$. Thus, it appears that both the excess of apoptosis and the lack of programed cell death can equally lead to an impairment of the cortical network and to cognitive defects.

\section{DENDRITES AND CONNECTIVITY}

The dendritic tree of PNs, with its long and extensively ramified branches, must be considered the main computational device of the neocortex (37). Therefore, it is not surprising that dendritic alterations are recognized as the key anatomical counterpart of MR (38). In experimental models of FASD based on early postnatal exposure, the basal dendritic arbor of PNs is more affected, as compared to the apical dendrite $[(4,5)$; see Figure 2]. Basal dendrites of L2/3 associative PNs in alcohol-treated rats display fewer dendritic branches than in controls, suggesting a defect of branching rather than of terminal dendrite elongation (6). This dissociation can be justified by the different molecular machinery involved in the two distinct phenomena of branching and terminal elongation (39). In the Ts65Dn mouse model of Down syndrome, the basal dendrites of L2/3 PNs, similarly to what observed in FASD, display a reduced complexity of the branching pattern (40). However, in humans affected by Down syndrome, dendritic alterations follow a complex temporal sequence, resulting in a simplification that is more dramatic for apical dendrites (41). A Golgi study by Armstrong and coworkers (42) provides a direct comparison between the dendritic anomalies of Rett and Down syndrome, pointing out that basal dendrites of the frontal cortex in individuals affected by Rett syndrome are strongly impaired both in supraand infragranular layers, while apical dendrites are affected only in supragranular layers. In experimental models of early-onset hypothyroidism, finally, both apical and basal dendrites of PNs appear to be strongly reduced (43).

Understanding which dendritic domain of PNs is preferentially targeted by disorders associated to MR is not trivial. In fact, basal and apical dendrites not only display different branching patterns, but are also characterized by different functional properties and are likely to play distinctive roles in the cortical network. Apical dendrites receive long-range feedback input from higher order cortical areas (44) and display both $\mathrm{Ca}^{2+}$ and NMDA spikes, whereas basal dendrites support only NMDA spikes (45).

Another central issue concerning the relationship between dendrites and MR is represented by the density and distribution of dendritic spines. Most inputs synapsing upon PNs occur on these small protrusions, which are essential for the linear summation of excitatory potentials (46). Almost all disorders associated with MR feature alterations of the number and/or shape of dendritic spines (38). Although a systematic review of dendritic spine anomalies is beyond the aim of the present paper, it is worth mentioning that both a decreased and an increased number of spines can lead to MR. While a reduction of dendritic spines has been observed in experimental models of FASD [e.g., Ref. (47)], their number is significantly higher in fragile $\mathrm{X}$ mice (48). Once again, as already pointed out for neuronal populations (see above), also the dendritic spines seem to ensure the good functioning of PNs only if they reach an optimal number. Fewer or more spines, conversely, can equally lead to defective function.

Since each spine is thought to represent the site of at least one synaptic contact, quantitative and/or qualitative spine anomalies are likely to reflect alterations of cortical connectivity. Thus, dendritic alterations can be accompanied by a defect of axon outgrowth or pruning, as demonstrated for early exposure to ethanol $(49,50)$, for mouse models of Rett syndrome (51), and fragile $\mathrm{X}$ syndrome (52). The obvious consequence is a modified intracolumnar (53) and long-range connectivity (4). The main alterations observed in experimental models of MR are summarized in Table S1 in Supplementary Material.

\section{PN EXCITABILITY}

The excitability of PNs (i.e., the ability of generating action potentials in response to depolarizing current) depends primarily on the intrinsic membrane properties and, to some extent, on the cited complexity of the dendritic tree. In fact, PN dendrites are not merely passive cables, but they are also endowed with a great variety of active conductances (54). Dendritic voltage-gated channels, in turn, can influence the axo-somatic firing pattern of PNs (55). We have demonstrated that exposure to ethanol during the third trimester equivalent leads to a long-lasting reduction of excitability in L5 PNs (5). Such an impairment represents the consequence of decreased spikes in the $\mathrm{Ca}^{2+}$ electrogenesis zone of the apical dendrite. These spikes are usually mediated by voltage-gated $\mathrm{Ca}^{2+}$ channels and are accompanied by their somatic counterpart, consisting of a prominent afterdepolarization. Interestingly and in agreement with our observation, Sánchez-Alonso et al. (56), in a mouse model of congenital hypothyroidism, noted that hippocampal PNs showed a decreased afterdepolarization.

An alteration of $\mathrm{Ca}^{2+}$ signaling has been also observed in experimental models of fragile $\mathrm{X}$ syndrome (57). This condition, however, is rather characterized by hyperexcitability (58). Besides affecting the neuron excitability, the unreliability of $\mathrm{Ca}^{2+}$ signals can alter the neural plasticity, as consistently observed in experimental models of $\operatorname{MR}(57,59,60)$.

\section{CONCLUDING REMARKS}

It seems pretty clear that the different etiological factors involved in different types of MR converge upon a few basic mechanisms, regardless of the vast variety of molecular pathways leading to such disturbances. Most of these alterations impair the functional properties of the major cell type of the neocortex, i.e., the PN. Here, we have briefly described some of the main mechanisms at the basis of MR, concerning the number, the dendritic tree, the connections, and the excitability of PNs. However, the picture can be complicated by the possibility that some of the described alterations affect selectively discrete populations of PNs, or even discrete subregions of the same cell.

A further contribute to the complexity derives from the obvious consideration that, despite their high number, PNs are not the only determinant of cortical network properties. In fact, the interplay between PNs and GABAergic interneurons is a key element of cortical physiology (24). Early exposure to alcohol results in a change of cortical interneurons, with a significant increase 
of calretinin cells (7). These neurons usually co-express VIP and contact other interneurons, thus mediating disinhibition of PNs, possibly driven by feedback input from higher cortical areas (61). Therefore, the decreased intrinsic excitability of the distal apical dendrite observed in FASD (5) can be counterbalanced under certain circumstances by a relative increase of the network-mediated disinhibitory pathway.

Another puzzling issue is the apparently opposite tendency of some anatomical and electrophysiological properties in different forms of MR, as is the case for hypo- and hyperexcitability. However, this is not necessarily a contradiction, at least in terms of the functional outcome. In fact, both hypo- and hyperexcitability can equally contribute to flatten the current-frequency curve, with a reduction of the dynamic range of PNs and a consequent impairment of the ability to encode relevant information (62).

\section{SUPPLEMENTARY MATERIAL}

The Supplementary Material for this article can be found online at http://www.frontiersin.org/Journal/10.3389/fped.2014. 00086/abstract

\section{REFERENCES}

1. Cajal SR. Recuerdos de mi Vida. Part 2. Historia de mi Labor Cientifíca. Madrid: Pueyo (1923).

2. Moore CI, Carlen M, Knoblich U, Cardin JA. Neocortical interneurons: from diversity, strength. Cell (2010) 142:189-93. doi:10.1016/j.cell.2010.07.005

3. Toesca A, Giannetti S, Granato A. Overexpression of the p75 neurotrophin receptor in the sensori-motor cortex of rats exposed to ethanol during early postnatal life. Neurosci Lett (2003) 342:89-92. doi:10.1016/S0304-3940(03)00258-1

4. Granato A, Di Rocco F, Zumbo A, Toesca A, Giannetti S. Organization of corticocortical associative projections in rats exposed to ethanol during early postnatal life. Brain Res Bull (2003) 60:339-44. doi:10.1016/S0361-9230(03)00052-2

5. Granato A, Palmer LM, De Giorgio A, Tavian D, Larkum ME. Early exposure to alcohol leads to permanent impairment of dendritic excitability in neocortical pyramidal neurons. J Neurosci (2012) 32:1377-82. doi:10.1523/JNEUROSCI. 5520-11.2012

6. Granato A, Van Pelt J. Effects of early ethanol exposure on dendrite growth of cortical pyramidal neurons: inferences from a computational model. Dev Brain Res (2003) 142:223-7. doi:10.1016/S0165-3806(03)00094-4

7. Granato A. Altered organization of cortical interneurons in rats exposed to ethanol during neonatal life. Brain Res (2006) 1069:23-30. doi:10.1016/j. brainres.2005.11.024

8. Lübke J, Feldmeyer D. Excitatory signal flow and connectivity in a cortical column: focus on barrel cortex. Brain Struct Funct (2007) 212:3-17. doi:10.1007/s00429-007-0144-2

9. Larkum ME, Waters J, Sakmann B, Helmchen F. Dendritic spikes in apical dendrites of neocortical layer 2/3 pyramidal neurons. J Neurosci (2007) 27:8999-9008. doi:10.1523/JNEUROSCI.1717-07.2007

10. Bureau I, von Saint Paul F, Svoboda K. Interdigitated paralemniscal and lemniscal pathways in the mouse barrel cortex. PLoS Biol (2006) 4:e382. doi:10.1371/journal.pbio.0040382

11. Yoshimura Y, Dantzker JL, Callaway EM. Excitatory cortical neurons form finescale functional networks. Nature (2005) 433:868-73. doi:10.1038/nature03252

12. Connors BW, Gutnick MJ. Intrinsic firing patterns of diverse neocortical neurons. Trends Neurosci (1990) 13:99-104. doi:10.1016/0166-2236(90)90185-D

13. Kasper EM, Larkman AU, Lübke J, Blakemore C. Pyramidal neurons in layer 5 of the rat visual cortex. I. Correlation among cell morphology, intrinsic electrophysiological properties, and axon targets. J Comp Neurol (1994) 339:459-74. doi:10.1002/cne.903390403

14. Schubert D, Staiger JF, Cho N, Kötter R, Zilles K, Luhmann HJ. Layer-specific intracolumnar and transcolumnar functional connectivity of layer $\mathrm{V}$ pyramidal cells in rat barrel cortex. J Neurosci (2001) 21:3580-92.

15. Schubert D, Kötter R, Luhmann HJ, Staiger JF. Morphology, electrophysiology and functional input connectivity of pyramidal neurons characterizes a genuine layer Va in the primary somatosensory cortex. Cereb Cortex (2006) 16:223-36. doi:10.1093/cercor/bhi100
16. Grewe BF, Bonnan A, Frick A. Back-Propagation of physiological action potential output in dendrites of slender-tufted L5A pyramidal neurons. Front Cell Neurosci (2010) 4:13. doi:10.3389/fncel.2010.00013

17. Morita K, Morishima M, Sakai K, Kawaguchi Y. Reinforcement learning: computing the temporal difference of values via distinct corticostriatal pathways. Trends Neurosci (2012) 35:457-67. doi:10.1016/j.tins.2012.04.009

18. Kress GJ, Yamawaki N, Wokosin DL, Wickersham IR, Shepherd GM, Surmeier DJ. Convergent cortical innervation of striatal projection neurons. Nat Neurosci (2013) 16:665-7. doi:10.1038/nn.3397

19. Thomson AM. Neocortical layer 6, a review. Front Neuroanat (2010) 4:13. doi:10.3389/fnana.2010.00013

20. Ledergerber D, Larkum ME. Properties of layer 6 pyramidal neuron apical dendrites. J Neurosci (2010) 30:13031-44. doi:10.1523/JNEUROSCI.2254-10.2010

21. Elston GN. Cortex, cognition and the cell: new insights into the pyramidal neuron and prefrontal function. Cereb Cortex (2003) 13:1124-38. doi:10.1093/ cercor/bhg093

22. Wang Y, Markram H, Goodman PH, Berger TK, Ma J, Goldman-Rakic PS. Heterogeneity in the pyramidal network of the medial prefrontal cortex. Nat $\mathrm{Neu}$ rosci (2006) 9:534-42. doi:10.1038/nn1670

23. Larkum ME, Nevian T, Sandler M, Polsky A, Schiller J. Synaptic integration in tuft dendrites of layer 5 pyramidal neurons: a new unifying principle. Science (2009) 325:756-60. doi:10.1126/science.1171958

24. Palmer L, Murayama M, Larkum ME. Inhibitory Regulation of Dendritic Activity in vivo. Front Neural Circuits (2012) 25:6-26. doi:10.3389/fncir.2012. 00026

25. Larkum ME. A cellular mechanism for cortical associations: an organizing principle for the cerebral cortex. Trends Neurosci (2013) 36:141-51. doi:10.1016/j. tins.2012.11.006

26. Valenzuela CF, Morton RA, Diaz MR, Topper L. Does moderate drinking harm the fetal brain? Insights from animal models. Trends Neurosci (2012) 35:284-92. doi:10.1016/j.tins.2012.01.006

27. Miller MW. Migration of cortical neurons is altered by gestational exposure to ethanol. Alcohol Clin Exp Res (1993) 17:304-14. doi:10.1111/j.1530-0277.1993. tb00768.x

28. Miller MW. Limited ethanol exposure selectively alters the proliferation of precursor cells in the cerebral cortex. Alcohol Clin Exp Res (1996) 20:139-43. doi:10.1111/j.1530-0277.1996.tb01056.x

29. Dobbing J, Sands J. Comparative aspects of the brain growth spurt. Early Hum Dev (1979) 3:79-83. doi:10.1016/0378-3782(79)90022-7

30. Ikonomidou C, Bittigau P, Ishimaru MJ, Wozniak DF, Koch C, Genz K, et al. Ethanol-induced apoptotic neurodegeneration and fetal alcohol syndrome. Science (2000) 287:1056-60. doi:10.1126/science.287.5455.1056

31. Olney JW, Wozniak DF, Jevtovic-Todorovic V, Farber NB, Bittigau P, Ikonomidou C. Glutamate and GABA receptor dysfunction in the fetal alcohol syndrome. Neurotox Res (2002) 4:315-25. doi:10.1080/1029842021000010875

32. Olney JW, Tenkova T, Dikranian K, Qin YQ, Labruyere J, Ikonomidou C. Ethanol-induced apoptotic neurodegeneration in the developing C57BL/6 mouse brain. Dev Brain Res (2002) 133:115-26. doi:10.1016/S0165-3806(02) 00279- 1

33. Kumar A, Sinha RA, Tiwari M, Pal L, Shrivastava A, Singh R, et al. Increased pro-nerve growth factor and p75 neurotrophin receptor levels in developing hypothyroid rat cerebral cortex are associated with enhanced apoptosis. Endocrinology (2006) 147:4893-903. doi:10.1210/en.2006-0027

34. Takeuchi D, Hirabayashi T, Tamura K, Miyashita Y. Reversal of interlaminar signal between sensory and memory processing in monkey temporal cortex. Science (2011) 331:1443-7. doi:10.1126/science.1199967

35. Cheng Y, Corbin JG, Levy RJ. Programmed cell death is impaired in the developing brain of FMR1 mutants. Dev Neurosci (2013) 35:347-58. doi:10.1159/ 000353248

36. Dastidar SG, Bardai FH, Ma C, Price V, Rawat V, Verma P, et al. Isoform-specific toxicity of Mecp2 in postmitotic neurons: suppression of neurotoxicity by FoxG1. J Neurosci (2012) 32:2846-55. doi:10.1523/JNEUROSCI.5841-11.2012

37. London M, Häusser M. Dendritic computation. Annu Rev Neurosci (2005) 28:503-32. doi:10.1146/annurev.neuro.28.061604.135703

38. Kaufmann WE, Moser HW. Dendritic anomalies in disorders associated with mental retardation. Cereb Cortex (2000) 10:981-91.

39. Yacoubian TA, Lo DC. Truncated and full-length TrkB receptors regulate distinct modes of dendritic growth. Nat Neurosci (2000) 3:342-9. doi:10.1038/73911

40. Dierssen M, Benavides-Piccione R, Martínez-Cué C, Estivill X, Flórez J, Elston GN, et al. Alterations of neocortical pyramidal cell phenotype in the Ts65Dn 
mouse model of Down syndrome: effects of environmental enrichment. Cereb Cortex (2003) 13:758-64.

41. Becker LE, Armstrong DL, Chan F. Dendritic atrophy in children with Down's syndrome. Ann Neurol (1986) 20:520-6.

42. Armstrong DD, Dunn K, Antalffy B. Decreased dendritic branching in frontal, motor and limbic cortex in Rett syndrome compared with trisomy 21 . J Neuropathol Exp Neurol (1998) 57:1013-7. doi:10.1097/00005072-19981100000003

43. Ipiña SL, Ruiz-Marcos A, Escobar del Rey F, Morreale de Escobar G. Pyramidal cortical cell morphology studied by multivariate analysis: effects of neonatal thyroidectomy, ageing and thyroxine-substitution therapy. Brain Res (1987) 465:219-29.

44. Cauller LJ, Clancy B, Connors BW. Backward cortical projections to primary somatosensory cortex in rats extend long horizontal axons in layer I. J Comp Neurol (1998) 390:297-310. doi:10.1002/(SICI)1096-9861(19980112)390:2<297: :AID-CNE11>3.3.CO;2-0

45. Nevian T, Larkum ME, Polsky A, Schiller J. Properties of basal dendrites of layer 5 pyramidal neurons: a direct patch-clamp recording study. Nat Neurosci (2007) 10:206-14. doi:10.1038/nn1826

46. Araya R, Eisenthal KB, Yuste R. Dendritic spines linearize the summation of excitatory potentials. Proc Natl Acad Sci U S A (2006) 103:18799-804. doi:10.1073/pnas.0609225103

47. Cui ZJ, Zhao KB, Zhao HJ, Yu DM, Niu YL, Zhang JS, et al. Prenatal alcohol exposure induces long-term changes in dendritic spines and synapses in the mouse visual cortex. Alcohol Alcohol (2010) 45:312-9. doi:10.1093/alcalc/agq036

48. Comery TA, Harris JB, Willems PJ, Oostra BA, Irwin SA, Weiler IJ, et al. Abnormal dendritic spines in fragile $\mathrm{X}$ knockout mice: maturation and pruning deficits. Proc Natl Acad Sci U S A (1997) 94:5401-4. doi:10.1073/pnas. 94.10.5401

49. Lindsley TA, Shah SN, Ruggiero EA. Ethanol alters BDNF-induced Rho GTPase activation in axonal growth cones. Alcohol Clin Exp Res (2011) 35:1321-30. doi:10.1111/j.1530-0277.2011.01468.x

50. Chen S, Charness ME. Ethanol disrupts axon outgrowth stimulated by netrin-1, GDNF, and L1 by blocking their convergent activation of Src family kinase signaling. J Neurochem (2012) 123:602-12. doi:10.1111/j.1471-4159.2012.07954.x

51. Belichenko PV, Wright EE, Belichenko NP, Masliah E, Li HH, Mobley WC, et al. Widespread changes in dendritic and axonal morphology in Mecp2-mutant mouse models of Rett syndrome: evidence for disruption of neuronal networks. J Comp Neurol (2009) 514:240-58. doi:10.1002/cne.22009

52. Patel AB, Loerwald KW, Huber KM, Gibson JR. Postsynaptic FMRP promotes the pruning of cell-to-cell connections among pyramidal neurons in the L5A neocortical network. J Neurosci (2014) 34:3413-8. doi:10.1523/JNEUROSCI. 2921-13.2014

53. Dani VS, Nelson SB. Intact long-term potentiation but reduced connectivity between neocortical layer 5 pyramidal neurons in a mouse model of Rett syndrome. J Neurosci (2009) 29:11263-70. doi:10.1523/JNEUROSCI.101909.2009
54. Migliore M, Shepherd GM. Emerging rules for the distributions of active dendritic conductances. Nat Rev Neurosci (2002) 3:362-70. doi:10.1038/nrn810

55. Larkum ME, Zhu JJ. Signaling of layer 1 and whisker-evoked $\mathrm{Ca}^{2+}$ and $\mathrm{Na}^{+}$ action potentials in distal and terminal dendrites of rat neocortical pyramidal neurons in vitro and in vivo. J Neurosci (2002) 22:6991-7005.

56. Sánchez-Alonso JL, Muñoz-Cuevas J, Vicente-Torres MA, Colino A. Role of lowvoltage-activated calcium current on the firing pattern alterations induced by hypothyroidism in the rat hippocampus. Neuroscience (2010) 171:993-1005. doi:10.1016/j.neuroscience.2010.10.003

57. Meredith RM, Holmgren CD, Weidum M, Burnashev N, Mansvelder HD. Increased threshold for spike-timing-dependent plasticity is caused by unreliable calcium signaling in mice lacking fragile X gene FMR1. Neuron (2007) 54:627-38. doi:10.1016/j.neuron.2007.04.028

58. Gibson JR, Bartley AF, Hays SA, Huber KM. Imbalance of neocortical excitation and inhibition and altered UP states reflect network hyperexcitability in the mouse model of fragile X syndrome. J Neurophysiol (2008) 100:2615-26. doi:10.1152/jn.90752.2008

59. Zucca S, Valenzuela CF. Low concentrations of alcohol inhibit BDNF-dependent GABAergic plasticity via L-type $\mathrm{Ca}^{2+}$ channel inhibition in developing CA3 hippocampal pyramidal neurons. J Neurosci (2010) 30:6776-81. doi:10.1523/ JNEUROSCI.5405-09.2010

60. Medina AE. Fetal alcohol spectrum disorders and abnormal neuronal plasticity. Neuroscientist (2011) 17:274-87. doi:10.1177/1073858410383336

61. Lee S, Kruglikov I, Huang ZJ, Fishell G, Rudy B. A disinhibitory circuit mediates motor integration in the somatosensory cortex. Nat Neurosci (2013) 16:1662-70. doi:10.1038/nn.3544

62. Pouille F, Marin-Burgin A, Adesnik H, Atallah BV, Scanziani M. Input normalization by global feedforward inhibition expands cortical dynamic range. Nat Neurosci (2009) 12:1577-85. doi:10.1038/nn.2441

Conflict of Interest Statement: The authors declare that the research was conducted in the absence of any commercial or financial relationships that could be construed as a potential conflict of interest.

Received: 02 July 2014; paper pending published: 19 July 2014; accepted: 25 July 2014; published online: 11 August 2014.

Citation: Granato A and De Giorgio A (2014) Alterations of neocortical pyramidal neurons: turning points in the genesis of mental retardation. Front. Pediatr. 2:86. doi: 10.3389/fped.2014.00086

This article was submitted to Child and Neurodevelopmental Psychiatry, a section of the journal Frontiers in Pediatrics.

Copyright (C) 2014 Granato and De Giorgio. This is an open-access article distributed under the terms of the Creative Commons Attribution License (CC BY). The use, distribution or reproduction in other forums is permitted, provided the original author(s) or licensor are credited and that the original publication in this journal is cited, in accordance with accepted academic practice. No use, distribution or reproduction is permitted which does not comply with these terms. 